\title{
Drug could stop PTSD before it starts
}

$\mathrm{R}$ esearchers investigating the genetic basis of posttraumatic stress disorder (PTSD) have found a drug that could stop the condition from developing if given shortly after a traumatic experience.

Kerry Ressler, a psychiatrist at Yerkes National Primate Research Center in Atlanta, Georgia, wanted to know why some people get posttraumatic stress disorder while others are more resilient. So he and his colleagues looked for genetic changes in a mouse model of PTSD.

Mice that had been through a traumatic experience - being held immobile on a board for two hours - exhibited symptoms similar to PTSD when exposed to a stressful situation a week later. These mice had altered expression of the gene Oprl1, which encodes an opioid receptor involved in fear memory consolidation in a brain region called the amygdala.

"When the Oprl1 pathway is activated, it acts as a brake on the fear system," says Ressler. "With prior stress, it is less active."

They also found evidence to suggest that the same gene is involved in fear learning and PTSD in humans. Ressler's group found two versions of Oprl1 that differed by just a single nucleotide. Victims of childhood abuse who carried one of the versions were more likely to suffer from symptoms of PTSD.

These findings point to a potential treatment that could prevent PTSD, says Ressler. When the mice were given a drug that activated the receptor encoded by Oprl1 shortly after the immobilization stress, it impaired the consolidation of fearful memories and prevented the development of PTSDlike symptoms.

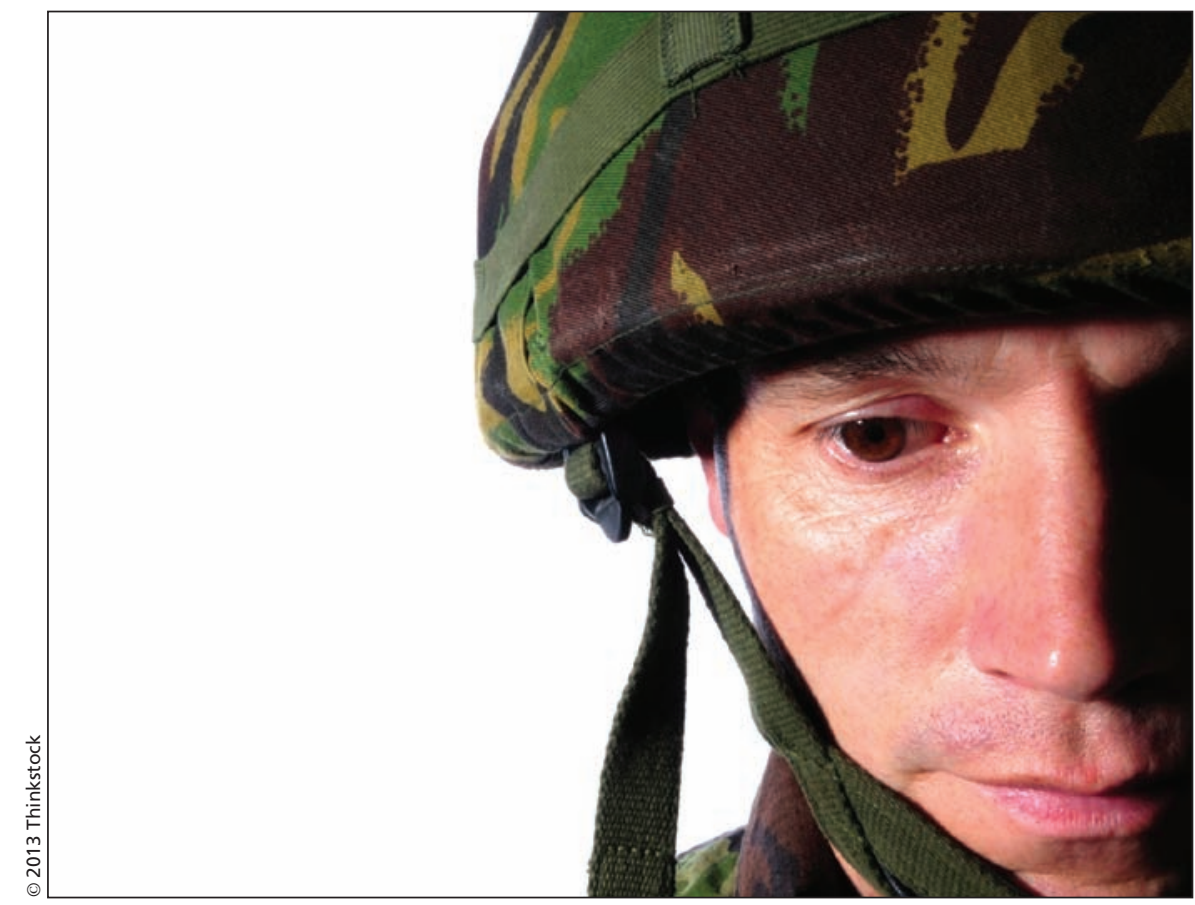

Mice undergoing stress had altered expression of the gene Oprl1, which encodes an opioid receptor involved in fear memory consolidation in a brain region called the amygdala. The researchers also found evidence to suggest that the same gene is involved in fear learning and PTSD in humans.

The research is at an early stage, but could lead to a drug that could be given to people shortly after a traumatic event, to stop the fearful memories from turning into PTSD. Similar results have been seen in humans given opiods like morphine in the aftermath of trauma, but such drugs carry the risk of long-term addiction. The drug used by Ressler does not produce the same reward effect as opiods, and so avoids that problem.

PTSD is a serious public health problem in Canada. Since 2001, more than 40000 Canadian Forces personnel have served in Afghanistan, and a 2011 study by the military found that $8 \%$ of them had been diagnosed with PTSD - similar to the level that is seen in the general population. These findings echo those in recent $C M A J$ research (www.cmaj.ca/lookup/doi /10.1503/cmaj.122120).

Ruth Lanius, director of the PTSD research unit at the University of Western Ontario in London, says that until now, most medications have focused on treating the symptoms of PTSD after they have developed, so the possibility that drugs could be used to stop the damage in its tracks is appealing.

"The earlier we can intervene, the better," she says. "The goal eventually should be to prevent PTSD from developing." - Brian Owens, St. Stephen, NB

CMAJ 2013. DOI:10.1503/cmaj.109-4533 